\title{
Functionally Graded Polyurethane/Cellulose Nanocrystal Composites
}

Jens C. Natterodt, ${ }^{a}$ Worarin Meesorn, ${ }^{a}$ Justin O. Zoppe, ${ }^{a}$ Christoph Weder ${ }^{a}{ }^{*}$

a Adolphe Merkle Institute, University of Fribourg, Chemin des Verdiers 4, 1700 Fribourg, Switzerland

\section{Email: christoph.weder@unifr.ch}

ABSTRACT: We here report the preparation and investigation of functionally graded polymer nanocomposites, which have a concentration gradient of cellulose nanocrystals (CNCs) along one direction. As a testbed, a series of nanocomposites consisting of a thermoplastic polyurethane (PU) and 0-15\% w/w CNCs was prepared via solvent casting and the mechanical properties of films of these materials were characterized by dynamic mechanical analyses (DMA) and tensile tests. The formation of graded materials was accomplished by lamination of films with varying CNC content. The processing conditions were optimized to achieve intimate fusion of the individual layers. The elimination of internal interfaces was evidenced by an elongation at break of up to $500 \%$. In order to explore potential applications of graded PU/CNC nanocomposites, structure-dependent actuation in response to water was demonstrated in a bio-inspired architecture. In addition, the damping behavior of cylindrical shaped composites was investigated by way of compression tests. The results show that functionally graded PU/CNC composites show good damping behavior over a much larger range of forces than the neat $\mathrm{PU}$ or the homogeneous nanocomposites.

Keywords: cellulose nanocrystals, CNCs, nanocomposite, gradient, processing. 


\section{INTRODUCTION}

Structural heterogeneities are ever-present in nature and often give rise to properties far superior to homogeneous structures with the same components. ${ }^{[1]}$ The microscopic gradient structure of bamboo, for instance, is one of the driving forces behind its high tensile and impact strength and thus its unique ability to withstand extreme environmental conditions. ${ }^{[2]}$ Taking such inspiration from nature, materials scientists and engineers have been developing new functionally graded materials (FGMs) that are less vulnerable to damage caused by mechanical forces or chemical reactions, ${ }^{[3]}$ and/or which enable specific functions ${ }^{[4]}$ Such gradient materials function partly through the redistribution of mechanical stresses across interfaces between the dissimilar components. Applications of FGMs include dental and medical implants, bullet-proof vests and barrier coatings, among others. ${ }^{[5]}$ One convenient approach to create FGMs is to produce polymer nanocomposites that comprise a nanofiller with a concentration gradient along one or multiple directions. Materials that contain different filler concentrations in a spatially resolved manner are found in a variety of biological structures, such as the above mentioned bamboo, plant stems, and bone, in which gradients are often generated by a change in stacking density of layers of different hardness. ${ }^{[3,6-8]}$ The interface between hard and soft layers in engineered gradient materials, however, can be a point of weakness without adequate covalent or non-covalent interactions ${ }^{[8]}$ This is often the consequence of a chemical mismatch between dissimilar components. Whereas heat treatment or adhesives are most often applied to increase interfacial adhesion between polymers of dissimilar hardness, a gradient in hardness may allow improved interfacial adhesion and toughness. 
Gradients in both metallic and polymeric systems can be achieved by various processing techniques, as summarized by Kieback et al. ${ }^{[9]}$ Such techniques include the preparation of monomer/filler mixtures prior to centrifugation, ${ }^{[10,11]}$ lamination, ${ }^{[12]}$ or a temperature gradient during processing. ${ }^{[13]}$ Furthermore, synthetic processes, such as frontal polymerization with continuous feeding of monomers with computercontrolled peristaltic pumps, have been developed for the preparation of graded copolymers. ${ }^{[14]}$ Of all these techniques, lamination is a desirable process for the production of functionally graded polymer nanocomposites due to its scalability. ${ }^{[15-17]}$

Due to their outstanding mechanical properties, cellulose nanocrystals (CNCs) have been used for over two decades as a reinforcing filler in polymers. ${ }^{[18]}$ CNCs are mechanically rigid rod-like particles with dimensions in the nanometer range and an attractive combination of properties, that include low density, high mechanical strength and aspect ratio, low cost, and low overall environmental impact. ${ }^{[19-25]}$ With respect to sustainability, a further appealing characteristic of CNCs is their wide availability from many biological sources such as wood,,[26] cotton, ${ }^{[27]}$ onion or citrus waste,${ }^{[28,29]}$ algae,${ }^{[30]}$ tunicates, ${ }^{[18]}$ banana, ${ }^{[31]}$ and bacterial sources. ${ }^{[32]}$ The available data also seem to suggest that, under realistic doses and exposure scenarios, CNCs have, unlike other nanofillers, a limited associated toxic potential. ${ }^{[33-36]}$ As a result of their high demand in academic research and projected use in industrial applications, several companies have recently started the commercial production of CNCs on a scale of up to $1000 \mathrm{~kg}$ per day. ${ }^{[25]}$ It is anticipated that CNCs will soon become viable alternatives to current polymer fillers such as stainless steel or glass fibers. ${ }^{[19]}$

CNCs have been used to reinforce a variety of polymers, including industrial highvolume products such as low-density polyethylene (LDPE), ${ }^{[37,38]}$ high-density polyethylene (HDPE), ${ }^{[39]}$ polypropylene (PP), ${ }^{[40]}$ polyvinyl chloride (PVC), ${ }^{[41]}$ 
polystyrene (PS), ${ }^{[42]}$ and thermoplastic polyurethanes (TPUs). ${ }^{[43]}$ Functionally graded materials in which CNCs are used to create a compositional gradient promise several advantages over similar materials with carbon-based fillers, ${ }^{[7,10,11]}$ notably low cost and toxicity, high strength and stiffness. Also attractive is the possibility to moderate the hydrogen-bonding interactions among the CNCs or between CNCs and a matrix polymer, ${ }^{[44,45]}$ which enables creating mechanically adaptive materials ${ }^{[46-48]}$ and shape-memory composites ${ }^{[49]}$ Interestingly, only a few examples of FGMs containing CNCs (or other forms of nanocellulose) have been reported to date. For example, CNCs were functionalized with allyl moieties that enabled cross-linking via photoinduced thiol-ene chemistry. ${ }^{[15]}$ Such CNCs were homogeneously incorporated into a poly(vinyl acetate) matrix and property gradients were achieved by controlling the UV light-induced cross-link density in a spatially resolved manner; this process resulted in materials with a gradient in mechanical properties, water-uptake, and water-induced mechanical changes. A similar approach was used to create functionally graded nanocomposites based on a rubbery ethylene oxide/epichlorohydrin copolymer and CNCs that had been derivatized with photoreactive benzophenone moieties. ${ }^{[50]}$ Zhang et al. reported bilayer structures that were based on two types of CNCs, which were functionalized with either a low or a high concentration of non-polar surface groups. ${ }^{[16]}$ Such bilayer films, which did not contain a polymer matrix, exhibited humidity-triggered actuation, as a result of the different polarity and water-uptake of the two layers. Functionally graded nanocellulose composites can, of course, also be created by incorporating the filler in a graded manner. This was, for example, achieved by adjacent placing of gels containing a polymer and different amounts of cellulose nanofibrils, followed by solvent evaporation. ${ }^{[16]}$ Limitations of this approach include the costs and 
environmental issues of solvents, the time of solvent evaporation, and the mixture of adjacent compositions during evaporation, resulting in discontinuous gradients.

Here, we report on the fabrication of functionally graded polymer nanocomposites, in which a concentration gradient of CNCs along one direction was accomplished by lamination of films with varying CNC content. For reasons of convenience, and in order to rapidly create a series of materials with different CNC concentrations, nanocomposites of a thermoplastic polyurethane and different concentrations of CNCs were first prepared via solvent casting, and films of different compositions were subsequently assembled into compositionally and functionally graded structures by layering and subsequent heating under moderate external compression. However, as several studies have shown that similar polymer/CNC nanocomposites can be made in solvent-free processes by melt-mixing, ${ }^{[43,51]}$ and co-extrusion ${ }^{[52,53]}$ and multicomponent injection molding processes are routine processes, ${ }^{[54]}$ it appears that the graded materials studied here can also be accessed using processing methods that would be more useful from a technological point of view.

\section{EXPERIMENTAL SECTION}

Materials. Tecoflex SG-80A (PU, an aliphatic polyether-based thermoplastic polyurethane), was obtained from Lubrizol. Tetrahydrofuran (THF), Rhodamine B isothiocyanate, and Brilliant Blue G were purchased from Sigma-Aldrich and were used as received. CNCs were extracted by sulfuric acid hydrolysis from Whatman No. 1 filter paper according to a previously reported procedure. ${ }^{[5]}$ The CNCs had dimensions of $190 \pm 80 \mathrm{~nm} \times 22 \pm 3 \mathrm{~nm}$ (determined by transmission electron microscopy images) and a surface charge of $60 \mathrm{mmol} / \mathrm{kg}$ (Figures S1 - S2), which were in the same range as previously reported. ${ }^{[56]}$ 
Preparation of PU/CNC nanocomposites. Films of the neat PU and PU/CNC nanocomposites were prepared by solvent-casting from THF according to a previously reported method ${ }^{[56]}$ that was slightly modified. In order to visualize the gradient of the CNC concentration, the materials were colored by the addition of Rhodamine B isothiocyanate; this dye was employed as it was readily available and did not affect the mechanical properties of the nanocomposites (Figure S3). Different amounts of the dye $(0-0.12 \% \mathrm{w} / \mathrm{w}$ relative to the total weight of the dry composite, vide infra) were dissolved in THF, the solution was heated to $60^{\circ} \mathrm{C}$, and the polymer was added under vigorous stirring, at a concentration of $50 \mathrm{mg} / \mathrm{mL}$. After $3 \mathrm{~h}$ of stirring at the same temperature, $0-15 \% \mathrm{w} / \mathrm{w} \mathrm{CNCs}$ were added (relative to the total weight of the final nanocomposite), and the dispersion was stirred overnight at high speed. The mixture was then sonicated in a Sonoswiss SW3H ultrasonic bath for $3 \mathrm{~h}$, cast into poly(tetrafluoroethylene) Petri dishes, and films were obtained by drying in a ventilated oven at $50{ }^{\circ} \mathrm{C}$ overnight. Complete solvent removal was ensured by further drying in a vacuum oven at $50{ }^{\circ} \mathrm{C}$ for $24 \mathrm{~h}$. To obtain nanocomposite films with a homogeneous thickness, the solvent-cast films were compression-molded in a Carver press at $100^{\circ} \mathrm{C}$ between poly(tetrafluoroethylene) sheets and spacers with a thickness of $0.4 \mathrm{~mm}$. The films were heated for $3 \mathrm{~min}$ without pressure and for $3 \mathrm{~min}$ with 5 bar of pressure, before they were removed from the press and cooled to room temperature between the poly(tetrafluoroethylene) sheets under ambient conditions.

Unless otherwise noted, the dye content was $0 \% \mathrm{w} / \mathrm{w}$ for the neat PU, $0.0004 \% \mathrm{w} / \mathrm{w}$ for the $2.5 \% \mathrm{w} / \mathrm{w} \mathrm{PU} / \mathrm{CNC}$ composite, $0.0012 \% \mathrm{w} / \mathrm{w}$ for the $5 \% \mathrm{w} / \mathrm{w} \mathrm{PU} / \mathrm{CNC}$ composite, $0.004 \% \mathrm{w} / \mathrm{w}$ for the $7.5 \mathrm{w} / \mathrm{w}$ PU/CNC composite, $0.012 \% \mathrm{w} / \mathrm{w}$ for the $10 \% \mathrm{w} / \mathrm{w} \mathrm{PU} / \mathrm{CNC}$ composite, $0.04 \% \mathrm{w} / \mathrm{w}$ for the $12.5 \% \mathrm{w} / \mathrm{w} \mathrm{PU} / \mathrm{CNC}$ composite, and $0.12 \% \mathrm{w} / \mathrm{w}$ for the $15 \% \mathrm{w} / \mathrm{w}$ PU/CNC composite. Higher dye content THF solutions 
were obtained by directly dissolving the dye in the respective amount of heated THF, and lower dye content THF solutions were obtained by dilution of the former.

Fabrication of graded PU/CNC nanocomposite films. The fabrication of graded films is schematically depicted in Figure 2A. PU/CNC nanocomposites prepared via solution-casting and subsequent compression molding (thickness ca. $0.4 \mathrm{~mm}$ ) (vide supra) were cut into squares with a length of ca. $1.5 \mathrm{~cm}$. Four squares of the same composition were stacked on top of each other so that the stack of films with the same composition had a total a thickness of $1.6 \mathrm{~mm}$; these stacks were further combined to create graded structures. For example, four squares of the neat PU were stacked on the substrate, four squares of the $2.5 \% \mathrm{w} / \mathrm{w} \mathrm{PU} / \mathrm{CNC}$ composite were placed on top, followed by four squares of the $5 \% \mathrm{w} / \mathrm{w}$ PU/CNC composite, and this procedure was continued with all compositions. Four additional squares of the neat PU and of the $15 \% \mathrm{w} / \mathrm{w} \mathrm{PU} / \mathrm{CNC}$ composite were placed at the bottom and the top of the stack, respectively, in order to ensure that the peripheral regions of the samples produced had the appropriate dimensions needed for clamping to conduct mechanical measurements. The stacked films were heated in a Carver press between poly(tetrafluoroethylene) sheets at a pressure of 2 bar and a temperature $100{ }^{\circ} \mathrm{C}$ for $5 \mathrm{~min}$ in order to promote fusion of the interfaces. This process did not change the thickness of the multilayer stack significantly, which was ca. $15 \mathrm{~mm}$, due to the low temperature, low pressure and the large sample height, which resulted in a slow heat transfer from the top and bottom to the center of the sample. The multilayer stack was then cut into thin films (thickness ca. $0.5 \mathrm{~mm}$ ) using a razor blade; the cutting direction was perpendicular to the direction of the layers in the stack. The films were finally pressed at $100^{\circ} \mathrm{C}$ between poly(tetrafluoroethylene) sheets and $0.4 \mathrm{~mm}$ thick spacers for $3 \mathrm{~min}$ without pressure and for further $3 \mathrm{~min}$ with a pressure 
of 5 bar. The resulting gradient films with a thickness of $0.4 \mathrm{~mm}$ were cooled to room temperature between the poly(tetrafluoroethylene) sheets and cut into a rectangular shape with a width of $5.3 \mathrm{~mm}$ and a length of $40 \mathrm{~mm}$.

\section{Fabrication of homogeneous and graded PU/CNC nanocomposite cylinders. At} first, homogeneous cylindrical shapes were prepared by filling PU/CNC nanocomposites prepared by solvent casting (vide supra) into a cylindrical mold, which was opened to one side, with a diameter of ca. $6 \mathrm{~mm}$ and a height between 12 and $15 \mathrm{~mm}$ (Figure 3A). The mold was then heated to $130{ }^{\circ} \mathrm{C}$ for $5 \mathrm{~min}$ and the polymer composite was then pressed into the cylindrical shape as depicted in the Figure with small pressure ( $1.5 \mathrm{bar}, 5 \mathrm{~min}$ ) to ensure that the polymer filled only the mold while preventing the leakage of over-pressed polymer. The shaped nanocomposites were cooled by immersion in a water bath and used as obtained for compression tests with homogeneous PU/CNC nanocomposites. For graded nanocomposites, these cylinders were cut into thin, disk-shaped slices with a homogeneous thickness of ca. $1 \mathrm{~mm}$ using a razor blade; the cutting direction was perpendicular to the long axis (height) of the cylinder. One of these thin slices of each composition was then vertically stacked according to their composition (neat PU on the bottom, $15 \% \mathrm{w} / \mathrm{w} \mathrm{PU} / \mathrm{CNC}$ on the top), and the stack (height ca. $7 \mathrm{~mm}$ ) was transferred into the cylindrical mold and pressed and cooled as described before to obtain a cylindrical $0-15 \% \mathrm{w} / \mathrm{w}$ PU/CNC gradient nanocomposite.

Fabrication of PU - PU/CNC bilayer films. Films of the neat PU and a $15 \% \mathrm{w} / \mathrm{w}$ $\mathrm{PU} / \mathrm{CNC}$ nanocomposite were prepared in a similar way as described above, with the only difference that the neat PU was here, for an enhanced visual contrast, also dyed with $0.1 \%$ w/w Brilliant Blue $G$ dye. Films of both materials, which had the same thickness of $0.4 \mathrm{~mm}$ and similar width and length, were then stacked and heated at 
$100{ }^{\circ} \mathrm{C}$ between poly(tetrafluoroethylene) sheets and $0.8 \mathrm{~mm}$ spacers for $1 \mathrm{~min}$ without pressure and for $1 \mathrm{~min}$ with a pressure of 2 bar. The films were removed from the press and were cooled under ambient conditions between the poly(tetrafluoroethylene) sheets, and their thickness was found to be $0.8 \pm 0.05 \mathrm{~mm}$. Rectangular shapes with a length of $20 \mathrm{~mm}$ and a width of $5.3 \mathrm{~mm}$ were then cut from the middle of the bilayer film.

Swelling of PU and PU/CNC nanocomposites in water. To determine the water uptake of the neat PU and a $15 \% \mathrm{w} / \mathrm{w}$ PU/CNC nanocomposite, films with dimensions of $10 \mathrm{~mm} \times 5.3 \mathrm{~mm} \times 0.4 \mathrm{~mm}$ were weighed and placed into deionized water at room temperature. After periodic time intervals, the films were removed from the water, the surface was carefully dried with tissue paper (without pressing the film) for about $30 \mathrm{~s}$, and the films were weighed and placed back into deionized water. The film dimensions were kept the same for all samples, since the swelling behavior strongly depends on the film thickness. Average values were obtained from two samples per composition. Furthermore, mono- and bilayer films were placed into water to investigate their bending behavior. Figure 4B (Images 2, 6 and 10) illustrates how the films were arranged in the water at the beginning of the swelling experiment. In order to fix the films to a glass plate in a specific angle, in a first step a $2 \mathrm{~mm}$ thick film of neat, undyed PU was attached to the glass plate, on which it adhered without additional adhesive. In a second step, this neat PU film was softened by a temperature increase to ca. $100{ }^{\circ} \mathrm{C}$ and the mono- and bilayer films were attached to the neat PU film by pressing at an angle of ca. $45^{\circ}$ into the soft polymer matrix. The samples were then cooled down to fix their shape.

Materials Characterization. Dynamic mechanical analysis (DMA) measurements were performed using a TA Instruments Model Q800 with an amplitude of $15 \mu \mathrm{m}$, a 
frequency of $1 \mathrm{~Hz}$, and a heating rate of $5{ }^{\circ} \mathrm{C} / \mathrm{min}$, using samples of rectangular shape with a length of ca. $10 \mathrm{~mm}$, a width of $5.3 \mathrm{~mm}$ and a thickness of $0.4 \mathrm{~mm}$. Stress-strain measurements were performed on a Zwick/Roell Z010 tensile tester, which was equipped with a $200 \mathrm{~N}$ load cell; a strain rate of $100 \% /$ min was applied, and the sample dimensions were the same as for DMA measurements. The same instrument was also used for compression tests, for which a $10 \mathrm{kN}$ load cell was mounted and the tensile test setup was exchanged by a compression test setup. Samples used for compression tests had a cylindrical shape with a diameter of ca. $6 \mathrm{~mm}$ and a height of ca. $8 \mathrm{~mm}$.

\section{RESULTS AND DISCUSSION}

For the development of functionally graded CNC composites, a commercial thermoplastic, linear aliphatic polyurethane (PU) was used as a testbed, and nanocomposites with up to $15 \% \mathrm{w} / \mathrm{w}$ CNC content were prepared. The PU was quite soft at room temperature (Young's modulus 4.3 MPa) and could be formed under heat and pressure at $100{ }^{\circ} \mathrm{C}$; however sufficient flow for extrusion was not achieved below $155^{\circ} \mathrm{C}$. The CNCs employed here were isolated from cotton by sulfuric acid hydrolysis, as previously reported. ${ }^{[55]}$ Their dimensions $(190 \pm 80 \mathrm{~nm} \times 22 \pm 3 \mathrm{~nm})$ and surface charge $(60 \mathrm{mmol} / \mathrm{kg})$, as obtained by the analysis of TEM images and conductometric titration, respectively, were similar to the values reported in previous works (Figure S1 and Figure S2). ${ }^{[56,57]}$ For reasons of convenience and in order to create a series of materials with CNC concentrations, PU/CNC nanocomposite were first prepared as films via solvent casting from THF, which were subsequently assembled to functionally grades stacks (Figure 2). In order to visualize the compositional gradient, small amounts $(0-0.12 \% \mathrm{w} / \mathrm{w})$ of Rhodamine $\mathrm{B}$ isocyanate 
were added during preparation of the individual compositions (no dye was added to the neat polymer and the dye concentration was increased with the CNC content, see Experimental Section for details). This red dye was readily available and soluble in THF and did not influence the mechanical properties of the nanocomposites, as illustrated by the mechanical data shown in Figure S3. With the neat PU and individual nanocomposite films in hand, the mechanical properties of these materials were investigated by dynamic mechanical analysis (DMA).

Figure $1 \mathrm{~A}$ and $\mathrm{B}$ show representative DMA traces and stress-strain curves of the neat PU and PU/CNC composites with a CNC content of $2.5-15 \% \mathrm{w} / \mathrm{w}$ and average values of the storage modulus, Young's modulus, maximum strain, and maximum stress are listed in Table 1. The DMA data reveal an increase of the storage modulus with increasing $\mathrm{CNC}$ content, which is most pronounced in the rubbery regime, in agreement with previous studies. ${ }^{[23,24,32]}$ For example, the storage modulus at room temperature was increased from 4.3 MPa for the neat PU by a factor of 17 to $72 \mathrm{MPa}$ for the 15\% w/w PU/CNC nanocomposite. A similar trend was observed for the Young's modulus obtained from the low-strain regime of the stress-strain curves. The increase of the Young's modulus from 4.3 MPa for the neat PU to $33 \mathrm{MPa}$ for the $15 \% \mathrm{w} / \mathrm{w}$ PU/CNC nanocomposite was less pronounced than the increase of the storage modulus. This trend has previously been observed and may be attributable to the different thermal history of nanocomposites measured by DMA, which were cooled to $-100^{\circ} \mathrm{C}$ before the storage modulus was measured at $25^{\circ} \mathrm{C}$, and nanocomposites characterized by stress-strain measurements, which have never been cooled;:[58] as a result, the PU's soft segments may crystallize differently. In this work, the difference in crystallization might be more pronounced with increasing CNC content, as shown by the similar values for Young's and storage modulus for the neat 
polymer, and more than $100 \%$ difference for $15 \%$ w/w PU/CNC nanocomposites. Interestingly, unlike most of the previously reported polymer/CNC nanocomposites, the present $\mathrm{PU} / \mathrm{CNC}$ nanocomposites did not exhibit significant embrittlement vis à vis the neat polymer. A remarkable elongation at break of nearly $2000 \%$ was maintained for nanocomposites with up to $15 \% \mathrm{w} / \mathrm{w}$ CNCs, indicating an extreme elasticity, despite the high CNC content and increased strength. In comparison, the incorporation of only $11 \% \mathrm{w} / \mathrm{w}$ of CNCs into LDPE has been reported to result in a reduction of elongation at break from 180 to $6 \% .{ }^{[59]}$ This phenomenon is likely due to the combination of the inherently high elasticity of the PU matrix and the ability of the CNCs to form dynamic hydrogen bonds with the urethane linkages, which may compete with those of their percolating network. As observed for the strain at break, the stress at break also remained approximately constant between 16 and $24 \mathrm{MPa}$ for all compositions without a clear trend. An increase of the mechanical properties, such as Young's modulus and storage modulus, is typical for polymer/CNC nanocomposites and has been widely reported. ${ }^{[23,}{ }^{24},{ }^{32]}$

A

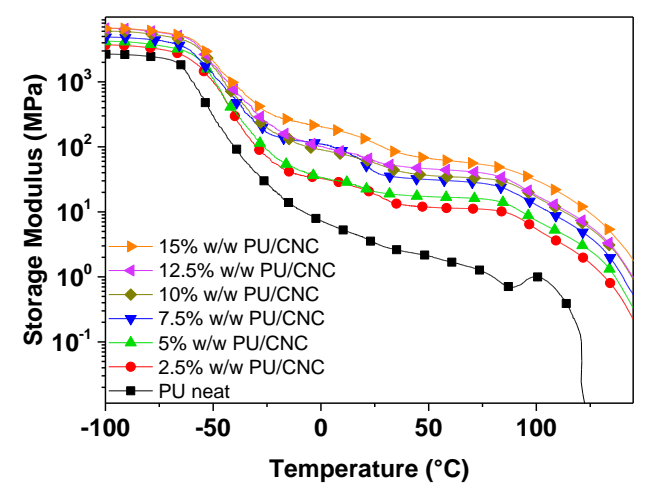

B

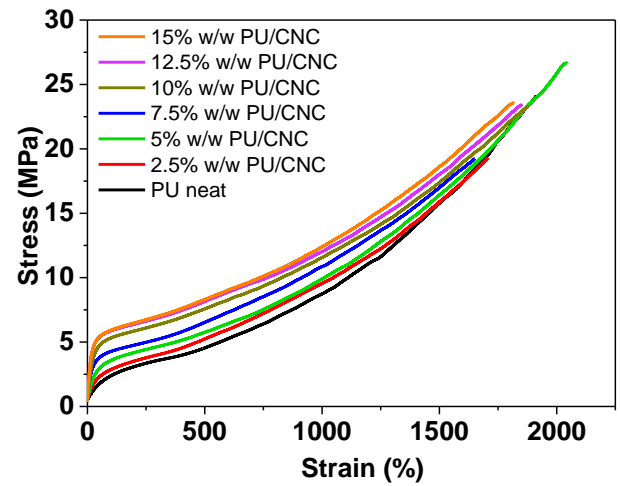

Figure 1. DMA traces $(A)$ and stress strain curves $(B)$ of the neat polyurethane (PU) and PU/CNC nanocomposites containing 2.5, 5, 7.5, 10, 12.5, or $15 \% \mathrm{w} / \mathrm{w}$ of CNCs. Shown are representative curves from at least 3 measurements per composition. 
Table 1. Storage modulus, Young's modulus, maximum strain and maximum stress of the neat PU and PU/CNC nanocomposites.

\begin{tabular}{lllll} 
& $\begin{array}{l}\text { Storage } \\
\text { Modulus at } \\
\mathbf{2 5}^{\circ} \mathbf{C}(\mathbf{M P a})^{\mathbf{a}}\end{array}$ & $\begin{array}{l}\text { Young's } \\
\text { Modulus } \\
(\mathbf{M P a})^{\mathbf{b}}\end{array}$ & $\begin{array}{l}\text { Max. Strain } \\
\mathbf{( \% )}^{\mathbf{b}}\end{array}$ & $\begin{array}{l}\text { Maximum } \\
\text { Stress (MPa) }\end{array}$ \\
PU neat & $4.3 \pm 0.9$ & $4.3 \pm 0.1$ & $1900 \pm 100$ & $24 \pm 2$ \\
2.5\% w/w PU/CNC & $17 \pm 3$ & $8.1 \pm 0.5$ & $1700 \pm 100$ & $17 \pm 1$ \\
$5 \% \mathrm{w} / \mathrm{w} \mathrm{PU} / \mathrm{CNC}$ & $21 \pm 1$ & $11 \pm 1$ & $2100 \pm 200$ & $26 \pm 1$ \\
$7.5 \% \mathrm{w} / \mathrm{w} \mathrm{PU} / \mathrm{CNC}$ & $42 \pm 3$ & $16 \pm 1$ & $1700 \pm 100$ & $16 \pm 1$ \\
10\% w/w PU/CNC & $54 \pm 3$ & $20 \pm 1$ & $1900 \pm 100$ & $23 \pm 1$ \\
$12.5 \% \mathrm{w} / \mathrm{w} \mathrm{PU} / \mathrm{CNC}$ & $63 \pm 5$ & $27 \pm 3$ & $1600 \pm 100$ & $24 \pm 1$ \\
$15 \% \mathrm{w} / \mathrm{w} \mathrm{PU} / \mathrm{CNC}$ & $72 \pm 6$ & $33 \pm 1$ & $1800 \pm 100$ & $18 \pm 1$ \\
\hline
\end{tabular}

${ }^{a}$ Data were acquired from DMA analyses. ${ }^{b}$ Determined by tensile tests at room temperature. All data are averages from at least three measurements per composition.

The process applied to prepare functionally graded nanocomposites from the abovediscussed PU/CNC films is illustrated in Figure 2A. Square shapes of similar dimensions were cut from films of the neat PU and the PU/CNC nanocomposites containing $2.5-15 \% \mathrm{w} / \mathrm{w} \mathrm{CNCs}$ and graded structures in which the CNC concentration increased from 0 to $15 \% \mathrm{w} / \mathrm{w}$ were prepared by stacking these films and compressing the stacks at $100{ }^{\circ} \mathrm{C}$. Subsequently, films were cut from the graded objects thus produced and compressed again at elevated temperature in order to homogenize their thickness and ensure intimate bonding of the interfaces. The intimate mixing across these interfaces is reflected by the visual appearance of the graded films (Figure 2A) in which the color change has become more gradual after the final 
compression molding step. Gratifyingly, the graded films are very robust and can be strained by more than $500 \%$ (Figure S4). The deformation behavior of the graded samples was modeled based on stress-strain data of the individual PU/CNC

A

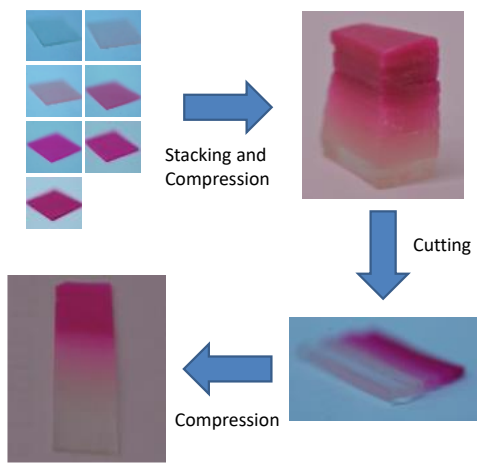

C

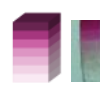

$0 \mathrm{MPa}$

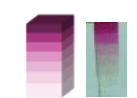

$2 \mathrm{MPa}$

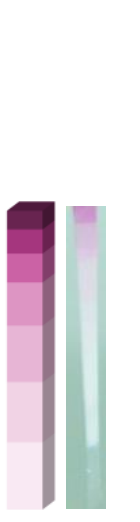

$6 \mathrm{MPa}$
B

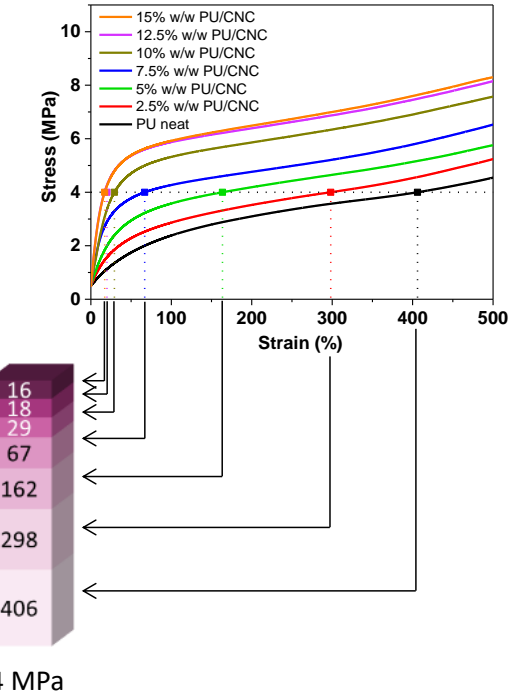

Figure 2. (A) Pictures illustrating the fabrication of PU/CNC nanocomposite films having a gradient in the CNC concentration along the long axis of the films. The materials were assembled from PU and PU/CNC nanocomposite films containing 0 , $2.5,5,7.5,10,12.5$, and $15 \% \mathrm{w} / \mathrm{w}$ CNCs and a red dye, whose concentration increased with the CNC content. (B) Magnification of the stress-strain curves of PU/CNC nanocomposites with $0-15 \%$ w/w CNCs shown in Figure 1B. Squares mark the strains adopted by these individual compositions at a stress of $4 \mathrm{MPa}$. These values were employed to construct the bar graph visualizing the hypothetical extension of a graded material assembled from the individual compositions at a stress of $4 \mathrm{MPa}$. The numbers represent the elongation, the color saturation reflects the $\mathrm{CNC}$ content (darker color = higher CNC content), and the elongations are drawn 
to scale. In the same manner, the corresponding bar graphs for other stresses were constructed, which are shown in (C) along with pictures of the graded composite film from (A) during a stress strain measurement at the same stresses.

nanocomposites, as shown in Figure 2B and Figure S5. The strains adopted by these individual compositions at a given stress were employed to construct bar graphs that visualize the expected extension of a graded material assembled from the individual compositions at the same stress (Figure 2B,C). The color saturations in the graphs reflect the CNC content (darker color = higher CNC content) and the elongations are drawn to scale. Figure $\mathbf{2 C}$ shows a comparison of these bar graphs along with pictures of a graded composite film that had been mounted in a tensile tester and was stretched with a strain rate of $100 \% / \mathrm{min}$. Images of the film were taken before the experiment and when the stress reached $2 \mathrm{MPa}, 4 \mathrm{MPa}, 6 \mathrm{MPa}$, and $8 \mathrm{MPa}$, respectively. While a precise numerical analysis of the deformation behavior of the graded materials is challenging (as the conversion of engineering stress and true stress in the graded structure is complex) the agreement of the bar graphs and the optical images shown in Figure $\mathbf{2 C}$ is excellent.

To investigate the compressive properties of graded PU/CNC composites, cylindrical shapes were produced in an appropriate mold, using a fabrication approach that mirrored the assembly of the films discussed above (Figure 3). First, compositionally homogeneous cylindrical objects of the neat PU and PU/CNC composites with CNC contents of $2.5-15 \% \mathrm{w} / \mathrm{w}$ were prepared by thermoforming the solvent-cast materials at $130{ }^{\circ} \mathrm{C}$ in a cylindrical mold (Figure $3 \mathbf{A}$ ). These cylinders were cut perpendicular to their long axis into thin, disk-shaped slices. Slices of different compositions were then vertically stacked, the stacks were placed in the cylindrical mold and compressed at $130{ }^{\circ} \mathrm{C}$ to obtain cylindrical objects in which the CNC concentration 
increased from 0 to $15 \% \mathrm{w} / \mathrm{w}$ along the cylinder axis (Figure 3B). The same process was used to prepare cylinders based on the neat PU and compositionally homogeneous PU/CNC composites with 7.5 and $15 \%$ w/w CNCs.

A

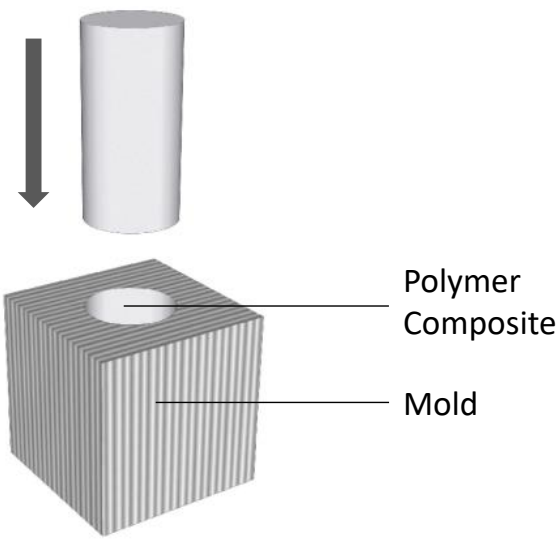

C
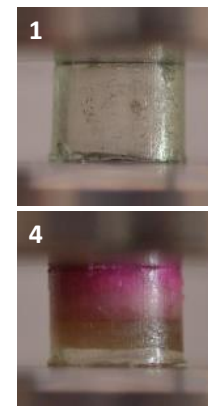

7

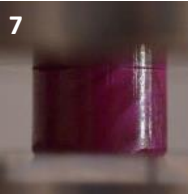

B
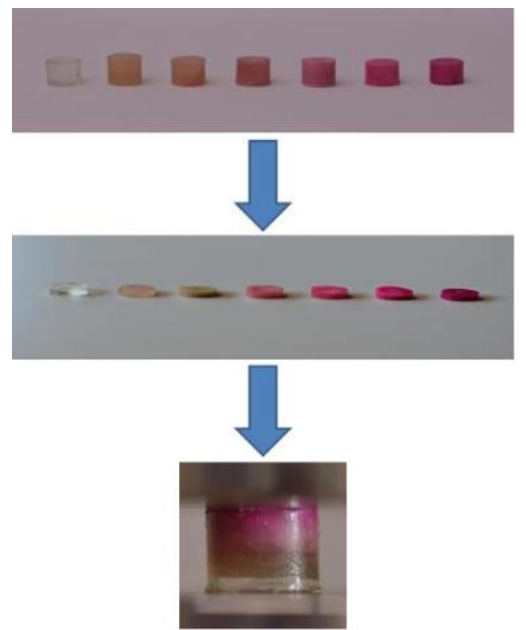

D

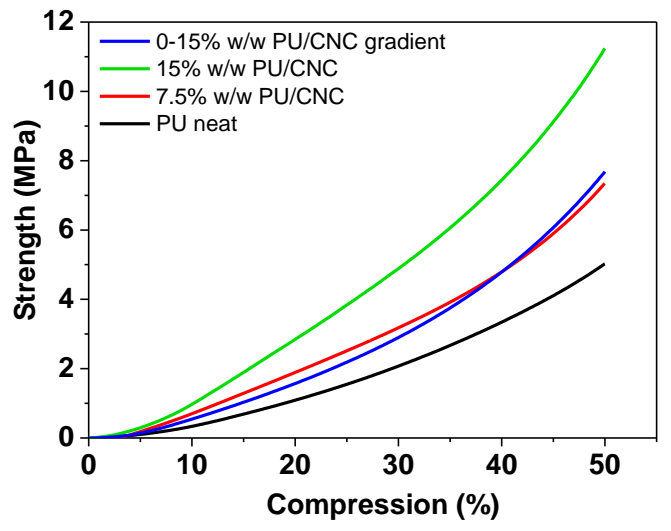

Figure 3. (A) Schematic of the mold used to prepare the cylinders shown in (B) and (C). (B) Pictures illustrating the preparation of PU/CNC nanocomposite cylinders with a CNC concentration gradient along the long axis. Cylinders of homogeneous composition (top, from left to right: $0,2.5,5,7.5,10,12.5,15 \% \mathrm{w} / \mathrm{w} \mathrm{CNC}$ ) were prepared by compression molding, cut into slices, which were assembled and compression molded again to form graded materials (bottom). (C) Pictures showing the compression of cylinders made from the neat PU (1-3), a graded material with CNC content ranging from $0-15 \% \mathrm{w} / \mathrm{w}(4-6)$ and a compositionally homogeneous $15 \% \mathrm{w} / \mathrm{w}$ 
PU/CNC nanocomposite (7-9). Each row shows the object before compression (left), after $50 \%$ compression (middle) and after relaxation (right). (D) Graph showing the results of compression tests of the neat PU, 7.5\% w/w PU/CNC, 15\% w/w PU/CNC and a PU/CNC gradient ranging from $0-15 \% \mathrm{w} / \mathrm{w}$.

The deformation behavior of the various materials upon compression is reflected by the pictures shown in Figure $\mathbf{3 C}$. The neat $\mathrm{PU}$ and the compositionally homogeneous PU/CNC composites showed a symmetric deformation behavior, with a moderate widening in the center of the samples. By contrast the functionally graded composite widened primarily in sections with low CNC content. While the neat PU displayed a complete return to its original shape due to its high elasticity (Figure $3 \mathbf{C}, 1-3$ ), the 15\% w/w PU/CNC composite exhibited some irreversible deformation (Figure 3C, 79 ), possibly due to a partial rearrangement of the CNC network. This effect was less pronounced for the functionally graded PU/CNC composite. In order to probe the usefulness of graded PU/CNC nanocomposite as damping materials, compression tests of the three materials shown in Figure $3 \mathrm{C}$ and a homogeneous $7.5 \% \mathrm{w} / \mathrm{w}$ PU/CNC nanocomposite were conducted (Figure 3D, Table 2). Upon introduction of $15 \% \mathrm{w} / \mathrm{w}$ CNCs, the compressive Young's modulus increased almost five-fold, from 1.6 to $7.3 \mathrm{MPa}$, whereas the compressive strength increased by a factor of 2-3, depending on the extent of compression. The homogeneous $7.5 \% \mathrm{w} / \mathrm{w} \mathrm{PU} / \mathrm{CNC}$ composite displayed mechanical characteristics that are approximately halfway between the neat PU and the 15\% w/w PU/CNC nanocomposite. Interestingly, the graded PU/CNC composite showed a nonlinear behavior; at 5\% compression, the strength $(0.13 \mathrm{MPa})$ was similar to that of the neat $\mathrm{PU}$, while at $50 \%$ compression the strength $(7.7 \mathrm{MPa})$ was much closer to that of the $7.5 \% \mathrm{w} / \mathrm{w}$ PU/CNC composite (7.3 $\mathrm{MPa})$. This finding can be explained by the higher elasticity and dominating 
mechanical properties of the neat PU at low compression, and an increasing influence of portions with higher CNC content at high compression. The crossover of the compressive stress-strain curves of the $7.5 \% \mathrm{w} / \mathrm{w} \mathrm{PU} / \mathrm{CNC}$ composite and the graded composite at intermediate strain further corroborates these results (Figure 3D). Importantly, the data show that the functionally graded PU/CNC composites show good damping behavior over a much larger range of forces than the neat PU or the homogeneous nanocomposites. Not surprisingly, the compressive Young's modulus (1.9 MPa) of the graded composite is not much higher than that of the neat $\mathrm{PU}(1.6 \mathrm{MPa})$; this is directly related to the fact that the moduli were measured at low compressive strains $(<2 \%)$, and at these strains, the compressive strength is dominated by the weakest part, which is the neat PU.

Table 2. Compressive Young's modulus, strength at $5 \%$ compression, and strength at $50 \%$ compression of PU/CNC nanocomposites. ${ }^{a}$

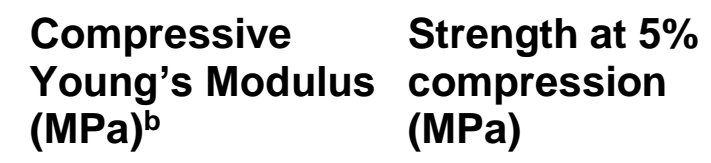

PU neat

$7.5 \% \mathrm{w} / \mathrm{w} \mathrm{PU} / \mathrm{CNC}$

$15 \% \mathrm{w} / \mathrm{w} \mathrm{PU} / \mathrm{CNC}$

$1.6 \pm 0.1$

$4.5 \pm 0.4$

$7.3 \pm 0.6$

$0-15 \mathrm{PU} / \mathrm{CNC}$ gradient ${ }^{\mathrm{c}} \quad 1.9 \pm 0.1$

\section{Strength at $5 \%$ \\ (MPa)}

$0.10 \pm 0.01$

$0.19 \pm 0.02$

$0.31 \pm 0.02$

$0.13 \pm 0.01$
Strength at $50 \%$ compression (MPa)

$5.0 \pm 0.2$

$7.3 \pm 0.3$

$11.2 \pm 0.3$

$7.7 \pm 0.2$

a Data were acquired from compression analyses as averages from at least three measurements per composition.

b Compressive Young's modulus was calculated as the slope between 1 and 2\% compression.

c Gradient materials contained CNC concentrations of $0,2.5,5,7.5,10,12.5$, and $15 \% \mathrm{w} / \mathrm{w}$ along the compression axis as shown in Figure 3A.

As another potential application of PU/CNC gradient materials, we explored the water-induced actuation. Since the aforementioned method to prepare gradient composites resulted in materials with a thickness of several millimeters, and complete swelling of such thick films in water would require long time periods to 
reach equilibrium, bilayer films consisting of the neat PU and the 15\% w/w PU/CNC nanocomposite with a total thickness of $0.8 \mathrm{~mm}$ were prepared for this purpose. Figure 4A illustrates the mass increase of reference films of the neat PU and the $15 \% \mathrm{w} / \mathrm{w} \mathrm{PU} / \mathrm{CNC}$ nanocomposite, and a bilayer structure of these two materials, upon immersion in water. The data clearly show that the neat PU swells only minimally in water. The weight increase of $1 \% \mathrm{w} / \mathrm{w}$ observed within the first 10 minutes is likely due to water adsorption on the polymer surface. On the other hand, the weight of the $15 \% \mathrm{w} / \mathrm{w} \mathrm{PU/CNC}$ nanocomposite film of the same dimensions increased within the first $24 \mathrm{~h}$ of immersion by $8 \% \mathrm{w} / \mathrm{w}$ and then remained approximately constant. For the fabrication of bilayer films, a neat PU film and a $15 \%$ w/w PU/CNC nanocomposite were vertically stacked and compressed with a spacer in order to prevent undesired polymer flow. In an attempt to mimic a pine cone, neat PU (Figure 4B, top), a bilayer (middle) and a 15\% w/w PU/CNC nanocomposite (bottom) were attached to a neat, non-colored PU film with an angle of ca. $45^{\circ}$ via heat treatment, which was subsequently attached to a glass substrate. The $15 \% \mathrm{w} / \mathrm{w}$ PU/CNC nanocomposite (pink) and the neat PU (blue) were dyed with Rhodamine and Brilliant Blue G, respectively, in order to facilitate visual inspection. Photographs where then taken before immersion in water (Figure 4B, 2, 6 and 10), after $24 \mathrm{~h}$ of immersion in water (Figure 4B, 3, 7 and 11), and after drying in vacuum for $24 \mathrm{~h}$ (Figure 4B, 4, 8 and 12). Whereas the neat PU and the 15\% w/w PU/CNC nanocomposite only displayed a gravity-induced bending (Figure 4B, 3 and 11) after immersion in water, the bilayer film (Figure 4B, 7) was bent upwards, against gravity, as a consequence of the increased water uptake of the $15 \% \mathrm{w} / \mathrm{w} \mathrm{PU} / \mathrm{CNC}$ layer compared to the neat PU layer. After drying in vacuum, all samples returned closely to their original state. Previous reports of water-responsive bilayer films based on 
cellulose stearoyl esters (CSEs) have shown a similar responsive behavior, however this was a result of differences in degree of substitution (DS) of stearoyl moieties in each layer. ${ }^{[16]}$ Even though mechanically adaptive composites have been reported previously with other nanofillers such as carbon nanotubes, ${ }^{[60]}$ we expect that the combination of the large contrast of mechanical properties typical for functionally graded polymer/CNC nanocomposites presented here and the high water uptake in the presence of CNCs, in general, will provide a unique platform for further development of water-responsive materials.

A

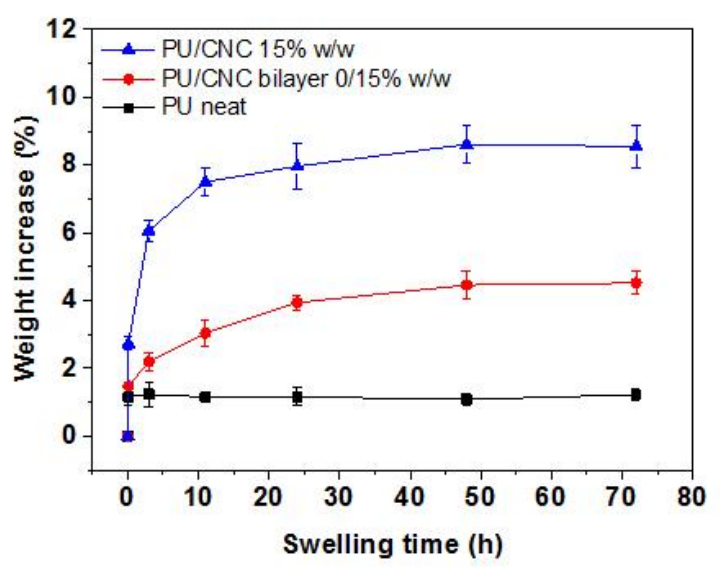

B
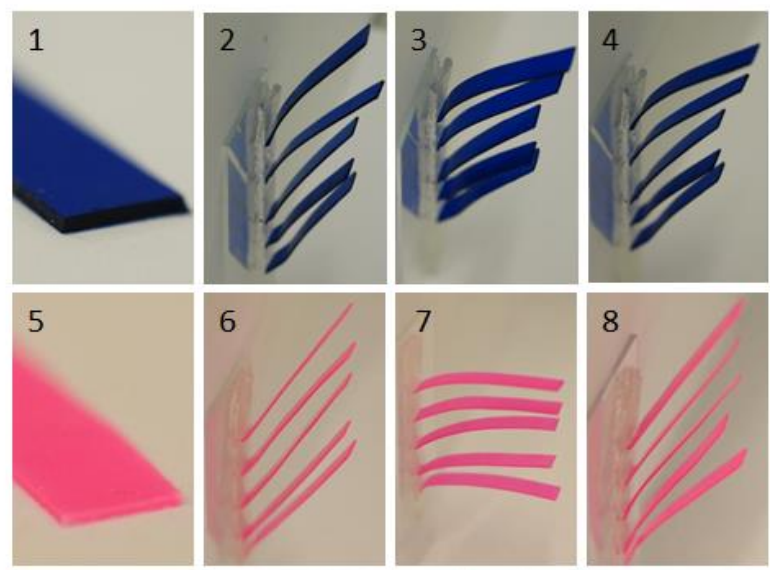

8

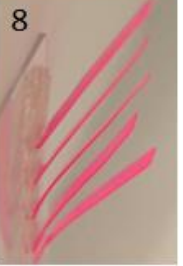

9
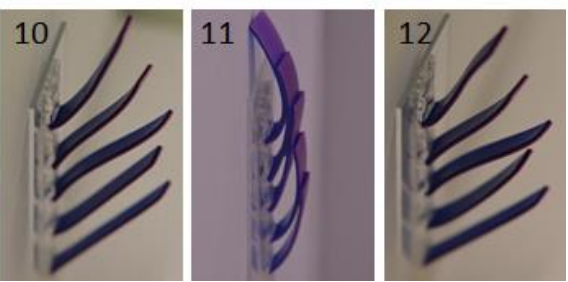
Figure 4. (A) Plot of the weight increase of films made from the neat PU, a $15 \% \mathrm{w} / \mathrm{w}$ PU/CNC composite, and a bilayer structure assembled from these two film types upon swelling in water at $25{ }^{\circ} \mathrm{C}$ for the time indicated. Data points represent averages of 2 samples per composition. (B) Pictures documenting the effect of swelling films of the neat PU (1-4), a 15\% w/w PU/CNC composite (5-8), and a bilayer structure consisting of a neat PU film (top, blue color) and a 15\% w/w PU/CNC nanocomposite (bottom, purple color) (9-12) and in water. Two different dyes Rhodamine (pink) and Brilliant Blue (blue) were added for visual purpose. The films were at first parallel attached to a film of neat PU by heating (2, 6 and 10$)$, then immersed into water for $24 \mathrm{~h} \mathrm{(3,7}$ and 11: after immersion), and then dried for $24 \mathrm{~h}$ under vacuum $(4,8$ and 12$)$.

\section{CONCLUSIONS}

In summary, functionally graded PU/CNC nanocomposites with a CNC content ranging from $0-15 \% \mathrm{w} / \mathrm{w}$ were prepared and shown to have excellent interfacial adhesion between compressed layers, as shown by elongation up to $500 \%$. In addition, the comparison of homogeneous nanocomposites with $0,7.5$, or $15 \% \mathrm{w} / \mathrm{w}$ CNC with a graded PU/CNC composite demonstrated the enhanced damping properties for a wider range of applied force for gradient materials due to heterogeneous stress transfer. The water-responsive behavior of a bilayer film composed of neat PU and the 15\% w/w PU/CNC nanocomposite contrasted that of a neat PU film and the $15 \% \mathrm{w} / \mathrm{w}$ PU/CNC nanocomposite, in which bilayers exhibited pine cone-mimetic curling against gravity upon immersion in water. The gradient formation process appears to be not only a convenient laboratory scale method, but should be adaptable also for medium and large scale processing methods. We 
envision that functionally graded polymer/CNC nanocomposites opens avenues toward novel gradient materials for such applications as bio-inspired actuators and damping devices.

\section{ACKNOWLEDGEMENTS}

The authors gratefully acknowledge financial support from the Swiss National Science Foundation (NRP66: Resource Wood, Nr. 406640_136911/1; 200020_152968; J.C. Natterodt, C. Weder. Ambizione Grant no. PZ00P2_167900; J.O. Zoppe) and the Adolphe Merkle Foundation.

Received: Month XX, XXXX; Revised: Month XX, XXXX; Published online: DOI: 


\section{REFERENCES}

[1] X. L. Wu, P. Jiang, L. Chen, J. F. Zhang, F. P. Yuan, Y. T. Zhu, Mater. Res. Lett. 2014, 2, 185.

[2] A. K. Ray, S. K. Das, S. Mondal, P. Ramachandrarao, J. Mater. Sci. 2004, 39, 1055.

[3] S. Suresh, Science 2001, 292, 2447.

[4] L. M. de Espinosa, W. Meesorn, D. Moatsou, C. Weder, Chem. Rev. 2017, 117, 12851.

[5] R. M. Mahamood, E. T. Akinlabi, M. Shukla, S. Pityana, Proc. World Congr. Eng. 2012, 3, 1593.

[6] D. Raabe, C. Sachs, P. Romano, Acta Mater. 2005, 53, 4281.

[7] K. Liew, Z. Lei, L. Zhang, Compos. Struct. 2015, 120, 90.

[8] G. Udupa, S. S. Rao, K. Gangadharan, Procedia Mater. Sci. 2014, 5, 1291.

[9] B. Kieback, A. Neubrand, H. Riedel, Mater. Sci. Eng. A. 2003, 362, 81.

[10] N. Lee, J. Jang, M. Park, C. Choe, J. Mater. Sci. 1997, 32, 2013.

[11] C. Klingshirn, M. Koizumi, F. Haupert, H. Giertzsch, K. Friedrich, J. Mater. Sci. Lett. 2000, 19, 263.

[12] E. Lund, Compos. Struct. 2009, 91, 158.

[13] E. Schäffer, S. Harkema, R. Blossey, U. Steiner, EPL (Europhysics Letters) 2002, 60, 255.

[14] D. Nuvoli, V. Alzari, J. A. Pojman, V. Sanna, A. Ruiu, D. Sanna, G. Malucelli, A. Mariani, ACS Appl. Mater. Interfaces 2015, 7, 3600.

[15] J. D. Fox, J. R. Capadona, P. D. Marasco, S. J. Rowan, J. Am. Chem. Soc. 2013, 135, 5167. 
[16] K. Zhang, A. Geissler, M. Standhardt, S. Mehlhase, M. Gallei, L. Chen, C. Marie Thiele, Sci. Rep. 2015, 5, 11011.

[17] B. Wang, A. J. Benitez, F. Lossada, R. Merindol, A. Walther, Angew. Chem. Int. Ed. 2016, 128, 6070.

[18] V. Favier, H. Chanzy, J. Y. Cavaille, Macromolecules 1995, 28, 6365.

[19] H. M. Azeredo, M. F. Rosa, L. H. C. Mattoso, Ind. Crops Prod. 2017, 97, 664.

[20] S. J. Eichhorn, Soft Matter 2011, 7, 303.

[21] C. Endes, S. Camarero-Espinosa, S. Mueller, E. Foster, A. Petri-Fink, B. RothenRutishauser, C. Weder, M. Clift, Nanobiotechnology 2016, 14, 78.

[22] D. Klemm, F. Kramer, S. Moritz, T. Lindström, M. Ankerfors, D. Gray, A. Dorris, Angew. Chem. Int. Ed. 2011, 50, 5438.

[23] M. Mariano, N. El Kissi, A. Dufresne, J. Polym. Sci. B 2014, 52, 791.

[24] R. J. Moon, A. Martini, J. Nairn, J. Simonsen, J. Youngblood, Chem. Soc. Rev. 2011, 40, 3941.

[25] D. Trache, M. H. Hussin, M. K. M. Haafiz, V. K. Thakur, Nanoscale 2017, 9, 1763.

[26] S. Beck-Candanedo, M. Roman, D. G. Gray, Biomacromolecules 2005, 6, 1048.

[27] J. F. Revol, L. Godbout, X. M. Dong, D. G. Gray, H. Chanzy, G. Maret, Liq. Cryst. 1994, 16, 127.

[28] J.-W. Rhim, J. P. Reddy, X. Luo, Cellulose 2015, 22, 407.

[29] M. Mariño, L. Lopes da Silva, N. Durán, L. Tasic, Molecules 2015, 20, 5908.

[30] Y. W. Chen, H. V. Lee, J. C. Juan, S.-M. Phang, Carbohydr. Polym. 2016, 151, 1210.

[31] S. Mueller, C. Weder, E. J. Foster, RSC Adv. 2014, 4, 907. 
[32] S. J. Eichhorn, A. Dufresne, M. Aranguren, N. E. Marcovich, J. R. Capadona, S. J. Rowan, C. Weder, W. Thielemans, M. Roman, S. Renneckar, W. Gindl, S. Veigel, J. Keckes, H. Yano, K. Abe, M. Nogi, A. N. Nakagaito, A. Mangalam, J. Simonsen, A. S. Benight, A. Bismarck, L. A. Berglund, T. Peijs, J. Mater. Sci. 2010, 45, 1.

[33] S. Camarero-Espinosa, C. Endes, S. Mueller, A. Petri-Fink, B. RothenRutishauser, C. Weder, M. J. D. Clift, E. J. Foster, Fibers 2016, 4.

[34] M. J. D. Clift, E. J. Foster, D. Vanhecke, D. Studer, P. Wick, P. Gehr, B. RothenRutishauser, C. Weder, Biomacromolecules 2011, 12, 3666.

[35] C. Endes, S. Camarero-Espinosa, S. Mueller, E. J. Foster, A. Petri-Fink, B. Rothen-Rutishauser, C. Weder, M. J. D. Clift, J. Nanobiotechnology 2016, 14. [36] C. Endes, S. Mueller, C. Kinnear, D. Vanhecke, E. J. Foster, A. Petri-Fink, C. Weder, M. J. D. Clift, B. Rothen-Rutishauser, Biomacromolecules 2015, 16, 1267. [37] A. J. de Menezes, G. Siqueira, A. A. Curvelo, A. Dufresne, Polymer 2009, 50, 4552.

[38] J. Sapkota, J. C. Natterodt, A. Shirole, E. J. Foster, C. Weder, Macromol. Mater. Eng. 2017, 302, 1.

[39] J. Li, Z. Song, D. Li, S. Shang, Y. Guo, Ind. Crops Prod. 2014, 59, 318.

[40] N. Ljungberg, C. Bonini, F. Bortolussi, C. Boisson, L. Heux, J.-Y. Cavaillé, Biomacromolecules 2005, 6, 2732.

[41] L. Chazeau, J. Cavaille, G. Canova, R. Dendievel, B. Boutherin, J. Appl. Polym. Sci. 1999, 71, 1797.

[42] O. J. Rojas, G. A. Montero, Y. Habibi, J. Appl. Polym. Sci. 2009, 113, 927.

[43] A. Nicharat, A. Shirole, E. J. Foster, C. Weder, J. Appl. Polym. Sci. 2017, 134, 45033. 
[44] R. Rusli, K. Shanmuganathan, S. J. Rowan, C. Weder, S. J. Eichhorn, Biomacromolecules 2010, 11, 762.

[45] R. Rusli, K. Shanmuganathan, S. J. Rowan, C. Weder, S. J. Eichhorn, Biomacromolecules 2011, 12, 1363.

[46] P. K. Annamalai, K. L. Dagnon, S. Monemian, E. J. Foster, S. J. Rowan, C. Weder, ACS Appl. Mater. Interfaces 2014, 6, 967.

[47] M. Jorfi, M. N. Roberts, E. J. Foster, C. Weder, ACS Appl. Mater. Interfaces 2013, 5, 1517.

[48] K. Shanmuganathan, J. R. Capadona, S. J. Rowan, C. Weder, Prog. Polym. Sci. 2010, 35, 212.

[49] J. Mendez, P. K. Annamalai, S. J. Eichhorn, R. Rusli, S. J. Rowan, E. J. Foster, C. Weder, Macromolecules 2011, 44, 6827.

[50] M. V. Biyani, M. Jorfi, C. Weder, E. J. Foster, Polym. Chem. 2014, 5, 5716.

[51] A. Nicharat, J. Sapkota, C. Weder, E. J. Foster, J. Appl. Polym. Sci. 2015, 132.

[52] C. Ryan, C. W. Christenson, B. Valle, A. Saini, J. Lott, J. Johnson, D. Schiraldi,

C. Weder, E. Baer, K. D. Singer, Adv. Mater. 2012, 24, 5222.

[53] H. Song, K. Singer, J. Lott, Y. Wu, J. Zhou, J. Andrews, E. Baer, A. Hiltner, C. Weder, J. Mater. Chem. 2009, 19, 7520.

[54] V. Piotter, J. Prokop, H.-J. Ritzhaupt-Kleissl, A. Ruh, J. Hausselt, Int. J. Adv. Manuf. Tech. 2010, 47, 63.

[55] J. R. Capadona, O. Van Den Berg, L. A. Capadona, M. Schroeter, S. J. Rowan, D. J. Tyler, C. Weder, Nat. Nanotechnol. 2007, 2, 765.

[56] J. C. Natterodt, J. Sapkota, E. J. Foster, C. Weder, Biomacromolecules 2017, $18,517$.

[57] L. Tang, C. Weder, ACS Appl. Mater. Interfaces 2010, 2, 1073. 
[58] J. C. Natterodt, A. Shirole, J. Sapkota, J. O. Zoppe, C. Weder, J. Appl. Polym. Sci. 2017, 45648.

[59] J. Sapkota, M. Jorfi, C. Weder, E. J. Foster, Macromol. Rapid Commun. 2014, 35, 1747.

[60] C. Li, E. T. Thostenson, T.-W. Chou, Compos. Sci. Technol. 2008, 68, 1227. 


\section{TOC GRAPHIC}

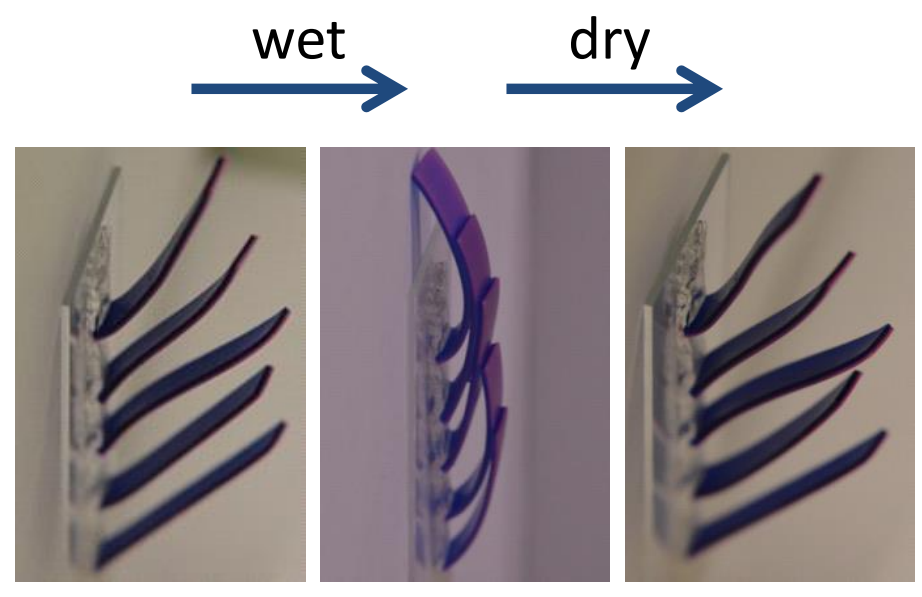

We here report a process to prepare functionally graded polymer nanocomposites, which have a concentration gradient of cellulose nanocrystals (CNCs) along one direction. The formation of graded materials was accomplished by lamination of films with varying CNC content. In order to explore potential applications of graded PU/CNC nanocomposites, structure-dependent actuation in response to water was demonstrated in a bio-inspired architecture. 